\title{
The effect of whole-body cooling on brain metabolism following perinatal hypoxic-ischemic injury
}

\author{
Elizabeth T. Corbo ${ }^{1}$, Brenda L. Bartnik-Olson², Sandra Machado ${ }^{2}$, T. Allen Merritt ${ }^{3}$, Ricardo Peverini ${ }^{3}$, Nathaniel Wycliffe ${ }^{2}$ \\ and Stephen Ashwal'
}

INTRODUCTION: Magnetic resonance imaging (MRI) and spectroscopy (MRS) have proven valuable in evaluating neonatal hypoxic-ischemic injury (HII).

RESULTS: MRI scores in the basal ganglia of $\mathrm{HII} / \mathrm{HT}^{+}$neonates were significantly lower than $\mathrm{HII} / \mathrm{HT}^{-}$neonates, indicating less severe injury and were associated with lower discharge encephalopathy severity scores in the HII/HT+ group $(P=0.01)$. Lactate (Lac) was detected in the occipital gray matter (OGM) and thalamus (TH) of significantly more HII/HT- neonates (31.6 and 35.3\%) as compared to the HII/HT+ group (10.5 and 15.8\%). In contrast, the $\mathrm{N}$-acetylaspartate (NAA)-based ratios in the OGM and $\mathrm{TH}$ did not differ between the HII groups.

DISCUSSION: Our data show that the HT was associated with a decrease in the number of HII neonates with detectable cortical and subcortical Lac as well as a decrease in the number of MRI-detectable subcortical lesions.

METHODS: We retrospectively compared the medical and neuroimaging data of $19 \mathrm{HIl}$ neonates who received $72 \mathrm{~h}$ of wholebody cooling $\left(\mathrm{HII} / \mathrm{HT}^{+}\right)$with those of 19 noncooled $\mathrm{HII}$ neonates $\left(\mathrm{HII} / \mathrm{HT}^{-}\right)$to determine whether hypothermia was associated with improved recovery from the injury as measured by MRI and MRS within the first 14 days of life. MRI scores and metabolite ratios of $\mathrm{HII} / \mathrm{HT}^{+}$and $\mathrm{HII} / \mathrm{HT}^{-}$neonates were also compared with nine healthy, nonasphyxiated "control" neonates.

$\mathbf{P}$ erinatal hypoxic-ischemic injury (HII) occurs in 1-2 per 1,000 live births and remains an important cause of perinatal mortality and long-term disability, accounting for $\sim 20 \%$ of individuals with cerebral palsy $(1,2)$. Until recently, HII treatment was supportive. However, the National Institute of Child Health and Human Development whole-body hypothermia trial showed a $28 \%$ reduction in death or moderate/severe disability at 18-22 months in treated as compared to nontreated neonates (3). In the Total Body Hypothermia for Neonatal Encephalopathy (TOBY) trial, neonates randomized to prolonged moderate hypothermia did not differ in the primary outcomes of death or disability at 18 months but showed reduced rates of cerebral palsy and improved mental and psychomotor outcomes as compared to neonates receiving standard care (4). These studies suggest that hypothermia is a promising treatment for reducing cerebral injury and improving neurological outcome after HII in term neonates.

Determining the severity of injury is exceedingly important in neonates with HII to shape medical interventions and to correctly advise the families regarding the likely outcome. Recent reviews have shown that the majority of variables used to predict outcome are limited in their accuracy $(5,6)$. Increasingly, MRI is used to assess the severity in newborns suffering many types of injuries, including hypoxia-ischemia. Both qualitative and quantitative scoring systems have proved useful in grading the severity of injury as well as in predicting neuromotor and cognitive outcomes $(7,8)$. MRI abnormalities associated with poor long-term outcomes include cortical highlighting, diffuse loss of gray/white matter differentiation, loss of signal in the posterior limb of the internal capsule, severe diffuse injury, and injury to the thalamus (TH) and basal ganglia (BG) $(9,10)$.

Magnetic resonance spectroscopy (MRS) and spectroscopic imaging (MRSI) have also proven valuable in evaluating HII. MRS measures brain metabolites, including $N$-acetylaspartate (NAA; neuronal integrity and mitochondrial function), creatine $(\mathrm{Cr})$ and phosphocreatine (brain energy metabolism and energy status), choline (Cho; membrane metabolism, integrity, and turnover), myo-inositol (astrocyte proliferation and brain osmotic balance), and glutamate/glutamine (glutamatergic neurotransmitter system). The indicators of HII include increased lactate (Lac) and decreased NAA levels in the BG and TH; these show significant correlation to poor outcomes and are detected using MRS (11-16).

To our knowledge, there are no studies that have examined the association between hypothermia and cerebral metabolism using MRS, although several publications have reported MRI findings (17-20). The primary aim of this study was to determine whether the HII neonates treated with hypothermia $\left(\mathrm{HII} / \mathrm{HT}^{+}\right)$showed fewer structural lesions and/or metabolic deficits as compared to noncooled HII (HII/ $\mathrm{HT}^{-}$) neonates or healthy neonates.

\section{RESULTS}

Clinical

Table 1 summarizes the demographic, laboratory and clinical data, as well as the discharge status of neonates in the

'Department of Pediatric Neurology, Loma Linda University Medical Center, Loma Linda, California; ${ }^{2}$ Department of Radiology, Loma Linda University Medical

Center, Loma Linda, California; ${ }^{3}$ Department of Neonatology, Loma Linda University Medical Center, Loma Linda, California. Correspondence: Stephen Ashwal (sashwal@llu.edu) 


\section{Articles $\mid$ Corbo et al.}

Table 1. Demographic data in control neonates and $\mathrm{HII}_{\mathrm{H}} \mathrm{HT}^{+}$and $\mathrm{HII}_{\mathrm{H}} \mathrm{HT}^{-}$groups

\begin{tabular}{|c|c|c|c|c|}
\hline & Control $(n=9)$ & $\mathrm{HII} / \mathrm{HT}^{+}(n=19)$ & $\mathrm{HII} / \mathrm{HT}^{-}(n=19)$ & $\mathrm{HII} / \mathrm{HT}^{+}$vs. $\mathrm{HII} / \mathrm{HT}^{-}$( $P$ value) \\
\hline \multicolumn{5}{|l|}{ Demographics } \\
\hline Gender (males:females) & $4: 5$ & $11: 8$ & $10: 9$ & - \\
\hline Sarnat score & 0 & $3(1-3)$ & $3(2-3)$ & NS \\
\hline Apgar at $1 \mathrm{~min}$ & $4(3-9)$ & $1(0-4)$ & $1(0-7)$ & NS \\
\hline Apgar at $10 \mathrm{~min}$ & $\mathrm{~N} / \mathrm{A}$ & $5(3-8)$ & $5(1-8)$ & NS \\
\hline Encephalopathy score & $\mathrm{N} / \mathrm{A}$ & $2(1-6)$ & $4(2-6)$ & $<0.01$ \\
\hline $\begin{array}{l}\text { Admission head } \\
\text { circumference }(\mathrm{cm})\end{array}$ & $\mathrm{N} / \mathrm{A}$ & $34.4 \pm 1.5$ & $33.1 \pm 3.9$ & NS \\
\hline Admission weight $(\mathrm{kg})$ & $\mathrm{N} / \mathrm{A}$ & $3.1 \pm 0.4$ & $3.2 \pm 0.6$ & NS \\
\hline $\mathrm{HCO}_{3}$ & $24.9 \pm 6.3$ & $25.0 \pm 4.5$ & $25.5 \pm 2.7$ & NS \\
\hline Serum Glc (mg/dl) & $\mathrm{N} / \mathrm{A}$ & $80.7 \pm 16.8$ & $88.5 \pm 15.6$ & NS \\
\hline Serum Lac (mmol/l) & $\mathrm{N} / \mathrm{A}$ & $1.7 \pm 0.8$ & $\mathrm{~N} / \mathrm{A}$ & - \\
\hline Serum $\mathrm{Na}(\mathrm{mmol} / \mathrm{l})$ & N/A & $142.8 \pm 5.1$ & $141.2 \pm 2.5$ & NS \\
\hline Serum $\mathrm{K}^{+}(\mathrm{mmol} / \mathrm{l})$ & $\mathrm{N} / \mathrm{A}$ & $4.4 \pm 0.8$ & $4.5 \pm 0.9$ & NS \\
\hline \multicolumn{5}{|l|}{ Clinical variables } \\
\hline $\begin{array}{l}\text { Need for advanced } \\
\text { resuscitation (\%) }\end{array}$ & $\mathrm{N} / \mathrm{A}$ & 100 & 95 & NS \\
\hline $\begin{array}{l}\text { Presence of multiorgan } \\
\text { dysfunction (\%) }\end{array}$ & $\mathrm{N} / \mathrm{A}$ & 68 & 93 & NS \\
\hline Home on AED (\%) & $\mathrm{N} / \mathrm{A}$ & 59 & 53 & - \\
\hline Head circumference $(\mathrm{cm})$ & $\mathrm{N} / \mathrm{A}$ & $35.3 \pm 1.6$ & $34.7 \pm 2.2$ & NS \\
\hline Weight (kg) & $\mathrm{N} / \mathrm{A}$ & $3.6 \pm 0.5$ & $3.6 \pm 0.8$ & NS \\
\hline
\end{tabular}

Values are reported as the mean \pm SD or median (minimum-maximum) for Sarnat, Apgar, and encephalopathy scores. Statistical differences between HII/HT+ and HII/HT- neonates were measured by independent samples $t$-test or Mann-Whitney test, with $P<0.05$ considered significant.

AED, antiepileptic drug; Glc, glucose; Hct, hematocrit; HII/HT+, hypoxic-ischemic injury with hypothermia therapy; HII/HT-, hypoxic-ischemic injury without hypothermia therapy; K, potassium; Lac, lactate; MRI, magnetic resonance imaging; Na, sodium; N/A, not available; NS, not significant. IInitial arterial pH in infant after birth.

study. At the time of the MRI/MRS, there were no differences in demographic characteristics, laboratory values, or clinical data between the HII/HT $\mathrm{HT}^{+}$and $\mathrm{HII} / \mathrm{HT}^{-}$groups. However, the discharge encephalopathy score was significantly lower in $\mathrm{HII} / \mathrm{HT}^{+}$neonates than in the HII/HT ${ }^{-}$group $(P<0.001$; Table 1).

\section{MRI}

When the MRI scores on the T1-weighted imaging, proton density-weighted imaging, T2-weighted imaging, and DWI sequences of $\mathrm{HII} / \mathrm{HT}^{+}$neonates were compared with those of $\mathrm{HII} / \mathrm{HT}^{-}$neonates, the $\mathrm{HII} / \mathrm{HT}^{+}$group showed significantly lower MRI scores (i.e., less injury) in the BG on all imaging sequences as well as a lower MRI score in the watershed region measured on the T1-weighted imaging (Table 2). There were no differences in the MR scores between HII/HT ${ }^{-}$and HII/ $\mathrm{HT}^{+}$neonates in the combined BG-watershed regions.

\section{MRS and MRSI}

Figure 1 shows the representative spectra from a singlevoxel spectroscopy acquisition (echo time, $\mathrm{TE}=20 \mathrm{~ms}$ ) in the OGM of control, $\mathrm{HII} / \mathrm{HT}^{+}$, and $\mathrm{HII} / \mathrm{HT}^{-}$neonates. Spectra from the HII/HT ${ }^{-}$and $\mathrm{HII} / \mathrm{HT}^{+}$neonates showed decreased NAA metabolite levels as compared with the spectrum from 
Table 2. MRI scores of neonates with $\mathrm{HIl}$ who did $\left(\mathrm{HII} / \mathrm{HT}^{+}\right)$and $\operatorname{did}$ not $\left(\mathrm{HII} / \mathrm{HT}^{-}\right)$undergo hypothermia

\begin{tabular}{|c|c|c|c|c|}
\hline & $\mathrm{HII} / \mathrm{HT}^{+}(n=19)$ & $\mathrm{HII} / \mathrm{HT}^{-}(n=19)$ & HIII/HT' vs. HII/HT' ( $P$ value) & $\begin{array}{l}\text { Correlation coefficient to } \\
\text { encephalopathy score }\end{array}$ \\
\hline BGT1W & $2(0-2)$ & $2(0-4)$ & 0.04 & $0.40(P=0.02)$ \\
\hline BGT2W & $0(0-2)$ & $2(0-4)$ & 0.03 & $0.44(P=0.01)$ \\
\hline BGDWI & $0(0-4)$ & $0(0-4)$ & 0.04 & $0.64(P<0.01)$ \\
\hline WT2W & $0(0-2)$ & $0(0-5)$ & 0.06 & NS \\
\hline WDWI & $0(0-5)$ & $0(0-5)$ & 0.64 & NS \\
\hline BGWT1W & $1(0-3)$ & $1(0-4)$ & 0.15 & NS \\
\hline BGW PDW & $1(0-3)$ & $1(0-4)$ & 0.61 & NS \\
\hline
\end{tabular}

Values are expressed as median and minimum-maximum values. Statistical differences were measured by one-way ANOVA with Bonferroni post hoc analysis. Correlation coefficients were determined using Spearman's $\rho$ analysis.

BGW, basal ganglia-watershed; DWI, diffusion-weighted imaging; NS, not significant; PDW, proton density-weighted imaging; T1W,T1 weighted;T2W,T2 weighted.

$P<0.05$ was considered significant.
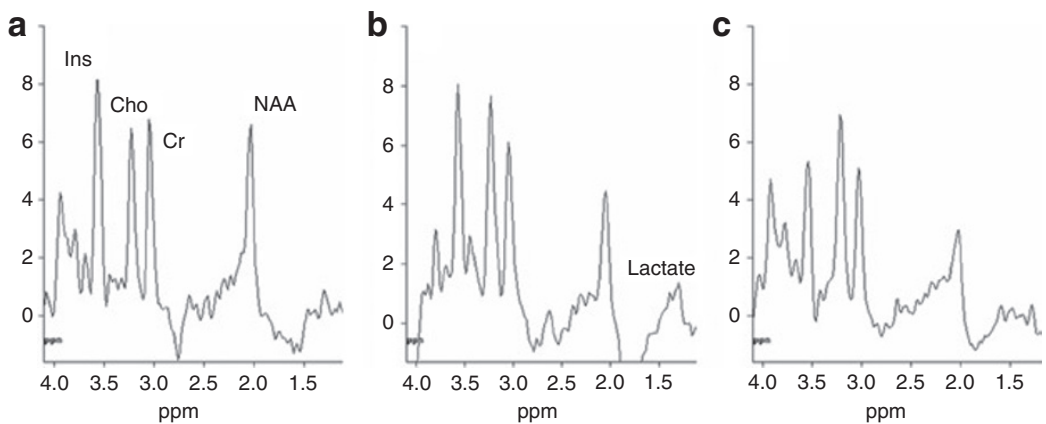

Figure 1. Representative spectra (echo time, $\mathrm{TE}=20 \mathrm{~ms}$ ) from the occipital gray matter of (a) control, (b) $\mathrm{HII}_{\mathrm{HT}} \mathrm{H}^{+}$, and $(\mathbf{c}) \mathrm{HII} / \mathrm{HT}^{-}$neonates. $\mathrm{NAA}$ is decreased in both the $\mathrm{HII} / \mathrm{HT}^{+}$and $\mathrm{HII} / \mathrm{HT}^{-}$neonates, as compared with controls. A lactate peak (1.33 ppm) is probably present in the spectra from the (b) $\mathrm{HII} / \mathrm{HT}^{+}$subject. Cho, choline; $\mathrm{Cr}$, creatine; $\mathrm{HII}_{\mathrm{HT}}{ }^{+}$, hypoxic-ischemic injury with hypothermia therapy; $\mathrm{HII}_{\mathrm{HT}}$, , hypoxic-ischemic injury without hypothermia therapy; Ins, myo-inositol; NAA, N-acetyl aspartate; ppm, parts per million.

a healthy neonate. A Lac peak (1.33 ppm) reflecting ischemic injury is shown in Figure $1 \mathbf{b}$.

Lac was present in the OGM in $31.6 \%$ of the $\mathrm{HII} / \mathrm{HT}^{-}$neonates as compared with $10.5 \%$ of the $\mathrm{HII} / \mathrm{HT}^{+}$neonates $(P<0.01)$. Lac was not observed in the OGM spectra of any of the control neonates. NAA levels were decreased in both the HII/HT- $(P$ $<0.01)$ and $\mathrm{HII} / \mathrm{HT}^{+}(P<0.01)$ groups as compared with the healthy controls (Table 3 ). The decrease in NAA resulted in lower $\mathrm{NAA} / \mathrm{Cr}(P=0.02)$ and NAA/Cho $(P<0.01)$ ratios in $\mathrm{HII} / \mathrm{HT}^{-}$ neonates, whereas only the NAA/Cho ratio was decreased $(P=$ 0.03 ) in the HII/ $/ \mathrm{HT}^{+}$group (Table 3). As compared to controls, there were no differences in $\mathrm{Cr}$, Cho, or myo-inositol metabolite levels or Cho/Cr or myo-inositol/Cr ratios in either HII group. There were no differences in any metabolite level or ratio between $\mathrm{HII} / \mathrm{HT}^{-}$and $\mathrm{HII} / \mathrm{HT}^{+}$groups (Table 3 ).

Figure 2 shows the representative spectra from a twodimensional MRSI acquisition (TE $=144 \mathrm{~ms})$ through the level of the BG and $\mathrm{TH}$ of control, $\mathrm{HII} / \mathrm{HT}^{-}$, and $\mathrm{HII} / \mathrm{HT}^{+}$neonates. A Lac peak can be seen in the BG of both HII neonates and the $\mathrm{TH}$ of the $\mathrm{HII} / \mathrm{HT}^{-}$neonates.

Table 4 summarizes the multivoxel data. Although it did not reach significance, Lac was present in the BG of fewer $\mathrm{HII} / \mathrm{HT}^{+}$ neonates $(15.8 \%)$ as compared to $35.3 \%$ of $\mathrm{HII} / \mathrm{HT}^{-}$neonates $(P=0.14)$. However, both HII groups showed significantly lower NAA/Cr and NAA/Cho ratios compared to the controls, with no difference observed between the two HII groups. In contrast, hypothermia appeared to differentially affect the metabolite ratios in the TH. First, significantly fewer $\mathrm{HII} / \mathrm{HT}^{+}$ neonates $(10.5 \%)$ had Lac peaks present in TH spectra as compared with $\mathrm{HII} / \mathrm{HT}^{-}$neonates $(29.4 \%, P=0.01)$. Second, NAA/Cr $(P<0.02)$ and NAA/Cho $(P<0.01)$ were significantly reduced in the TH of HII/HT' group as compared with controls, whereas no significant reduction in NAA/Cr and only a weakly significant $(P<0.05)$ reduction in NAA/Cho were detected in the $\mathrm{HII} / \mathrm{HT}^{+}$neonates. 


\section{Articles | Corbo et al.}

Table 3. Semiquantitative metabolite levels (in institutional units) and ratios in the mid-occipital gray matter of healthy neonates and neonates with $\mathrm{HIl}$ who did $\left(\mathrm{HII} / \mathrm{HT}^{+}\right)$and $\operatorname{did}$ not $\left(\mathrm{HII} / \mathrm{HT}^{-}\right)$receive hypothermia treatment

\begin{tabular}{|c|c|c|c|c|c|c|c|}
\hline & \multirow[b]{2}{*}{ Control $(n=9)$} & \multirow[b]{2}{*}{$\mathrm{HII} / \mathrm{HT}^{+}(n=19)$} & \multirow[b]{2}{*}{$\mathrm{HII} / \mathrm{HT}^{-}(n=19)$} & \multicolumn{3}{|c|}{$P$ value } & \multirow{2}{*}{$\begin{array}{c}\text { Correlation } \\
\text { coefficient to } \\
\text { encephalopathy } \\
\text { score }\end{array}$} \\
\hline & & & & Cvs. HII/HT+ & C vs. HII/HT- & $\mathrm{HII} / \mathrm{HT}^{+}$vs. HII/HT- & \\
\hline $\mathrm{Cr}$ & $4.12 \pm 0.81$ & $3.65 \pm 0.79$ & $3.19 \pm 1.26$ & 0.93 & 0.19 & 0.65 & $-0.50(P<0.01)$ \\
\hline Cho & $5.23 \pm 1.04$ & $5.22 \pm 1.19$ & $4.76 \pm 1.46$ & 1.00 & 1.00 & 0.97 & NS \\
\hline $\begin{array}{l}\% \text { Neonates } \\
\text { with Lac }\end{array}$ & 0 & 10.5 & 31.6 & & & $<0.01^{\mathrm{a}}$ & \\
\hline $\mathrm{NAA} / \mathrm{Cr}$ & $1.28 \pm 0.21$ & $1.07 \pm 0.16$ & $0.97 \pm 0.32$ & 0.15 & 0.02 & 0.68 & $-0.52(P<0.01)$ \\
\hline NAA/Cho & $1.01 \pm 0.23$ & $0.75 \pm 0.14$ & $0.65 \pm 0.27$ & 0.03 & $<0.01$ & 0.51 & $-0.52(P<0.01)$ \\
\hline $\mathrm{Cho} / \mathrm{Cr}$ & $1.29 \pm 0.18$ & $1.44 \pm 0.17$ & $1.73 \pm 0.91$ & 1.00 & 0.35 & 0.47 & $0.43(P=0.01)$ \\
\hline
\end{tabular}

Values are expressed as the group means \pm SD. Statistical differences were measured by one-way ANOVA with Bonferroni post hoc or $x^{2}$ analysis ( $\left.{ }^{(}\right)$. Correlation coefficients were determined using Spearman's $p$ analysis.

C, control; Cho, choline; Cr, creatine; HII/HT+, hypoxic-ischemic injury with hypothermia therapy; HII/HT-, hypoxic-ischemic injury without hypothermia therapy; Ins, myo-inositol; Lac, lactate; NAA, N-acetyl aspartate; NS, not significant.

$P<0.05$ was considered significant.
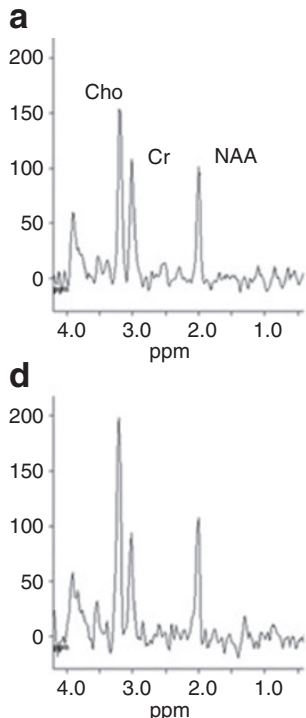
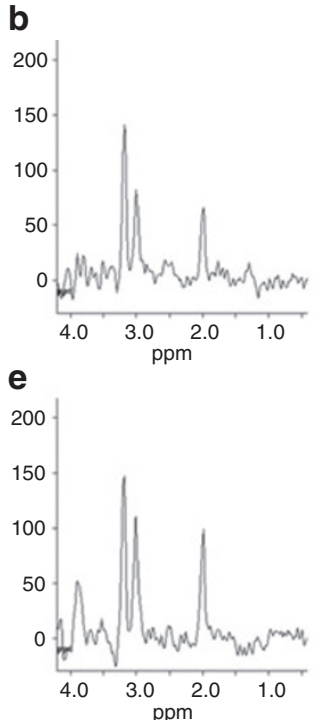
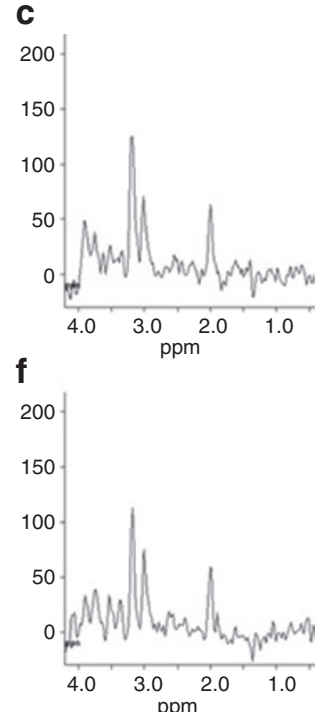

Figure 2. Spectra from a two-dimensional magnetic resonance spectroscopic imaging acquisition (echo time, $T E=144 \mathrm{~ms}$ ) through the basal ganglia (BG; top row) and thalamus (TH; bottom row). Spectra from (a,d) controls, (b,e) $\mathrm{HII}_{\mathrm{H}} \mathrm{HT}^{+}$neonates, and $(\mathbf{c}, \mathbf{f}) \mathrm{HII} / \mathrm{HT}^{-}$neonates. NAA levels from BG and TH are decreased in $\mathrm{HII} / \mathrm{HT}^{+}$and $\mathrm{HII} / \mathrm{HT}^{-}$neonates as compared to controls. Lactate $(1.33 \mathrm{ppm})$ is present in the BG and TH of (c,f) $\mathrm{HII}^{-\mathrm{HT}^{-}}$neonate and only in the BG of the (b) $\mathrm{HII} / \mathrm{HT}^{+}$neonate. Cho, choline; $\mathrm{Cr}$, creatine; $\mathrm{HII}_{\mathrm{HT}}{ }^{+}$, hypoxic-ischemic injury with hypothermia therapy; $\mathrm{HII} / \mathrm{HT}^{-}$, hypoxic-ischemic injury without hypothermia therapy; NAA, $N$-acetyl aspartate; ppm, parts per million.

Correlation of Imaging and Metabolic Data to Severity of Injury The relation between MRI scores, metabolite ratios, and encephalopathy score (severity of injury) was also evaluated. Only the BG imaging scores showed a significant correlation to the encephalopathy severity score (Table 2). The T1, proton density, and T2 data sets showed significant positive correlations with the strongest correlation seen with the DWI BG score (Spearman's $\rho$ 0.64; $P<0.001$ ). In addition, a positive correlation was seen between the DWI score in the combined
BG-watershed region and the encephalopathy score (Spearman's $\rho 0.42 ; P<0.01)$.

Metabolite data from all regions showed significant correlations to the severity of injury. OGM NAA and Cr levels and the NAA/Cr and NAA/Cho ratios showed significant negative correlations to the encephalopathy score, whereas Cho/Cr showed a significant positive correlation to the encephalopathy score (Table 3). Similarly, BG NAA/Cho and Cho/Cr ratios showed a significant correlation to the severity of encephalopathy 
Table 4. Metabolite ratios in the basal ganglia and thalami of healthy neonates and neonates with $\mathrm{HIl}$ who $\operatorname{did}\left(\mathrm{HII}_{\mathrm{H}} / \mathrm{HT}^{+}\right)$and $\operatorname{did}$ not $\left(\mathrm{HII} / \mathrm{HT}^{-}\right)$ receive hypothermia treatment

\begin{tabular}{|c|c|c|c|c|c|c|c|}
\hline & \multirow[b]{2}{*}{$\begin{array}{c}\text { Control } \\
(n=9)\end{array}$} & \multirow{2}{*}{$\begin{array}{l}\mathrm{HII} / \mathrm{HT}^{+} \\
(n=19)\end{array}$} & \multirow{2}{*}{$\begin{array}{l}\mathrm{HII} / \mathrm{HT}^{-} \\
(n=19)\end{array}$} & \multicolumn{3}{|c|}{$P$ value } & \multirow{2}{*}{$\begin{array}{c}\text { Correlation coefficient } \\
\text { to encephalopathy } \\
\text { score }\end{array}$} \\
\hline & & & & Cvs. HII/HT & Cvs. HII/HT- & $\mathrm{HII} / \mathrm{HT}^{+}$vs. HII/HT & \\
\hline \multicolumn{8}{|l|}{ Basal ganglia } \\
\hline $\mathrm{NAA} / \mathrm{Cr}$ & $1.07 \pm 0.07$ & $0.80 \pm 0.12$ & $0.83 \pm 0.15$ & $<0.01$ & $<0.01$ & 1.00 & $-0.12(P=0.51)$ \\
\hline NAA/Cho & $0.74 \pm 0.10$ & $0.57 \pm 0.09$ & $0.53 \pm 0.13$ & $<0.01$ & $<0.01$ & 0.74 & $-0.39(P=0.02)$ \\
\hline $\mathrm{Cho} / \mathrm{Cr}$ & $1.48 \pm 0.27$ & $1.44 \pm 0.07$ & $1.74 \pm 0.59$ & 1.00 & 0.50 & 0.11 & $0.46(P<0.01)$ \\
\hline \multicolumn{8}{|l|}{ Thalami } \\
\hline $\mathrm{NAA} / \mathrm{Cr}$ & $1.11 \pm 0.18$ & $0.97 \pm 0.17$ & $0.83 \pm 0.24$ & 0.39 & 0.02 & 0.17 & $-0.42(P=0.02)$ \\
\hline NAA/Cho & $0.78 \pm 0.10$ & $0.62 \pm 0.13$ & $0.51 \pm 0.18$ & 0.05 & $<0.01$ & 0.12 & $-0.57(P<0.01)$ \\
\hline $\mathrm{Cho} / \mathrm{Cr}$ & $1.46 \pm 0.31$ & $1.58 \pm 0.29$ & $1.59 \pm 0.40$ & 1.00 & 0.86 & 1.00 & $0.09(P=0.62)$ \\
\hline
\end{tabular}

Values are expressed as the group means \pm SD. Statistical differences were measured by one-way ANOVA with Bonferroni post hoc or $x^{2}$ analysis ( $\left.{ }^{(}\right)$. Correlation coefficients were determined using Spearman's $\rho$ analysis.

C, control; Cho, choline; Cr, creatine; HII/HT, hypoxic-ischemic injury with hypothermia therapy; Lac, lactate; NAA, N-acetyl aspartate; NS, not significant.

$P<0.05$ was considered significant.

(Spearman's $\rho-0.39 ; P=0.02$ and Spearman's $\rho 0.46 ; P<0.01$, respectively). NAA/Cr and NAA/Cho ratios in the TH also correlated to the severity of encephalopathy (Spearman's $\rho-0.42$; $P=0.02$ and Spearman's $\rho-0.49 ; P<0.01$ ).

\section{DISCUSSION}

In a retrospective review of clinical and neuroimaging data of 19 neonates who were treated with $72 \mathrm{~h}$ of whole-body cooling after a perinatal HII, we found a significant decrease in the presence of Lac in the OGM and TH and fewer MRI lesions in the BG region, suggestive of reduced severity of injury. Although MRI has been previously used to study the changes in neonates treated with hypothermia, to our knowledge, this is first study to report differences in cerebral metabolism between cooled and non-cooled HII neonates.

\section{MRI}

A number of studies have examined the MRI changes in neonates treated with hypothermia after HII. In one study, whole-body cooling was associated with fewer cortical abnormalities than in controls, a finding suggesting that cooling might have a cortical neuroprotective effect (17). A subsequent study using head or whole-body cooling showed a decrease in the number of moderate and severe BG and TH lesions as compared with HII neonates who did not undergo hypothermia (18). In this study, cortical abnormalities were less common in the head-cooling group as compared to neonates treated with whole-body cooling (18). In more recent reports, hypothermia was associated with a decrease in the number of BG or TH lesions $(19,20)$ as well as lesions in the white matter and posterior limb of the internal capsule but not in the cortical gray matter (19).

Similar to the studies of Rutherford and Bonifacio (18-20), we observed fewer lesions in the $\mathrm{BG}$ of $\mathrm{HII} / \mathrm{HT}^{+}$neonates as compared with the HII/HT- neonates. We did not detect differences in cortical injury between the two HII groups, which may be due to differences in the gestational age ( $\geq 38$ weeks) or severity of injury of neonates included in our study as compared with the earlier study (17).

\section{MRS}

MRS has also been shown to be beneficial in determining the extent of injury and neurological outcome after HII. Although there is no standard protocol for its use, MRS has proven helpful in detecting metabolic injury to vulnerable regions with high metabolic demand such as the BG and TH (21). Regardless of the technique, the most common MRS findings after HII are the presence of Lac and decreased NAA (14,15,22-24).

Using short-echo-time single-voxel spectroscopy in the OGM, we showed a significant decrease in the number of HII neonates with Lac after hypothermia, as compared to $\mathrm{HII}^{-\mathrm{HT}^{-}}$ neonates, suggesting an association with reduced severity of injury. We did not find a group difference in NAA-derived ratios between HII groups, which would suggest that hypothermia does not potentiate neuronal recovery after injury. However, MRS findings after HII are influenced by the duration of the time post-injury. Previous MRS studies in the HII population have shown that increased Lac can be seen as early as $18 \mathrm{~h}$ after injury and peaks $\sim 4-5$ days after injury $(11,25)$. Lac is a marker of increased anaerobic metabolism and is a consequence of reduced blood flow to the brain; thus many studies have concentrated on the early acquisition of MRI and MRS for prognosis $(12,16,26)$. Our finding that fewer $\mathrm{HII}^{+}$neonates had Lac might suggest a neuroprotective mitochondrial effect that may precede neuronal cellular recovery. Changes in NAA levels evolve more slowly and are not likely to diminish significantly until beyond $48 \mathrm{~h}$ (27). With the exception of four subjects, HII/ $\mathrm{HT}^{+}$neonates underwent MRI/MRS studies within $24-48 \mathrm{~h}$ of 
rewarming (Table 1). As a result, significant recovery of NAA levels due to cooling may not have developed. In a serial MRS study of children undergoing hypothermic cardiopulmonary bypass, a significant decrease in NAA metabolite levels at 2 days post-surgery was reported, which recovered to baseline (preoperative) levels by 5 days post-surgery (28). Additional studies to determine whether the interval between rewarming and MRS is a factor in the hypothermia population need to be conducted.

MRS of the BG and TH was also performed. Although not significant, the number of $\mathrm{HII} / \mathrm{HT}^{+}$neonates with $\mathrm{Lac}$ was reduced as compared with $\mathrm{HII} / \mathrm{HT}^{-}$neonates as observed in spectra from the BG (Table 4). We did not observe a difference in the NAA-based ratios of the BG between HII groups, with $\mathrm{NAA} / \mathrm{Cr}$ and NAA/Cho ratios remaining significantly lower than those of controls. In contrast, spectra from the TH of HII/ $\mathrm{HT}^{+}$neonates showed significantly lower Lac and higher NAA/ $\mathrm{Cr}$ ratios, as compared with the HII/HT- neonates. The differential effects of hypothermia on cerebral metabolites in the BG and TH are unclear. In most MRS studies in HII neonates, single-voxel techniques are used and positioned such that the voxel contains the lentiform nucleus and the ventrolateral $\mathrm{TH}$; thus separate data for the BG and $\mathrm{TH}$ are not collected. However, in a study by Angeles et al. (29), metabolite findings in the BG and TH of opioid-treated neonates also differed, with NAA/Cho ratios in the BG significantly lower than those of controls, whereas NAA-based ratios in the $\mathrm{TH}$ were at or near control values. It is possible that there may be regional metabolic tissue difference between the $\mathrm{BG}$ and $\mathrm{TH}$, which may contribute to the long-term outcome disability of certain forms of cerebral palsy (e.g., dyskinetic or choreoathetotic).

\section{Correlation of MRI and MRS Findings and Outcome}

The previous imaging studies of hypothermia-treated neonates showed a strong correlation between the number of structural lesions observed on MRI to both outcome and neurosensory impairments at 18 months of age (20,30). Moreover, Massaro et al. (31) showed that T2-weighted imaging signal intensity ratios in BG and TH of cooled neonates are predictive of death or severe neurological deficit. Although we do not have outcome data, our imaging findings in the BG did show a significant positive correlation to the discharge encephalopathy severity score (Table 2), suggesting that a greater number of imaging abnormalities (higher MRI scores) in the BG region are associated with more severe encephalopathy.

The NAA-based metabolite ratios in both the cortical and subcortical regions showed significant negative correlations with the discharge encephalopathy score. Because previous MRS studies in HII neonates have shown that reduced NAA/ $\mathrm{Cr}$ ratios correlate with impaired long-term developmental outcomes $(13,16)$, future studies may find that MRS findings in hypothermia-treated neonates have a similar value in determining long-term neurological outcomes.

\section{Study Limitations}

One potential limitation of our study is the difference in timing of the MRS examinations between groups (Table 1). In addition to injury-induced metabolite changes, the concentration of cerebral metabolites changes dramatically within the first few postnatal weeks $(32,33)$. The potentially rapid increase in NAA levels in the slightly older ( $~ 8$ days) controls compared to younger neonates in the HII groups may have contributed, in part, to the differences in the OGM and BG NAA levels, regardless of injury or treatment.

In addition, the presence of Lac and diffusion restriction diminish within the first 4-5 days after the HII (34), although a number of clinical studies have shown that elevated Lac levels can persist for a considerable amount of time after injury (36). Although the HII groups were imaged at slightly later time points (Table 1), it was the HII/HT- ${ }^{-}$group that showed the highest percentage of neonates with Lac (Tables 3 and 4) and higher BG imaging scores (Table 2), despite being imaged, on average, at 8 days. It is possible that our findings underestimate the number of neonates with MRI/MRS abnormalities and the magnitude of difference between HII groups. Because the time course of metabolite levels change following injury as well as with maturation, these variables should be evaluated in future studies.

To our knowledge, this is the first study to measure brain metabolism in both cortical (OGM) and subcortical (BG and $\mathrm{TH}$ ) regions of hypothermia-treated HII neonates and compare these findings to both noncooled HII and healthy neonates. Our findings show that hypothermia treatment following a perinatal HII is associated with a reduction in the number of neonates with Lac in cortical and subcortical regions as well as a reduced number of BG lesions. Future studies including follow-up will be helpful in determining whether these MRI/MRS changes reflect the severity of acute injury and whether this is helpful in more accurate assessment of long-term outcomes in hypothermia-treated neonates.

\section{METHODS \\ Clinical}

Informed consent was obtained and the study was approved by the Loma Linda University Medical Center Institutional Review Board. We retrospectively examined medical and neuroimaging data of 38 neonates with perinatal HII cared for in the Loma Linda University Medical Center neonatal intensive care unit (March 2000 through September 2010). Neonates who were diagnosed with HII and evaluated using MRI/MRS within the first 14 days of life were included. Criteria for hypothermia treatment were similar to those in the literature $(3,4)$ : Apgar score $\leq 5$ at $10 \mathrm{~min}$ of life, cord $\mathrm{pH}$ or any postnatal blood gas $\mathrm{pH}$ of $\leq 7.0$ at $\leq 1 \mathrm{~h}$, base deficit on cord gas or any postnatal blood gas of $\leq 16 \mathrm{mEq} / \mathrm{l}$ at $\leq 1 \mathrm{~h}$, continued need for ventilation initiated at or soon after birth for at least $10 \mathrm{~min}$ and the presence of moderate or severe encephalopathy as defined by Sarnat and Sarnat (30). Neonates were excluded from the hypothermia protocol if they were $<36$ weeks of gestation, had no evidence of HII or neurological depression, or if they had chromosomal or major congenital anomalies. We identified 19 neonates with perinatal injury who were treated for $72 \mathrm{~h}$ with wholebody hypothermia $\left(\mathrm{HII} / \mathrm{HT}^{+}\right)$and 19 neonates who met clinical criteria for HII but did not receive whole-body cooling $\left(\mathrm{HII} / \mathrm{HT}^{-}\right)$. Non-cooled neonates were matched to the $\mathrm{HII} / \mathrm{HT}^{+}$neonates based on the 5 -min Apgar scores as an early indicator of outcome severity. Control subjects were nine full-term neonates with no history of perinatal asphyxia who were admitted to the neonatal intensive care unit and underwent MRI/ MRS studies for a seizure-like event $(n=7)$ or episodes of apnea $(n=2)$. All control neonates had normal MRI/MRS studies. 


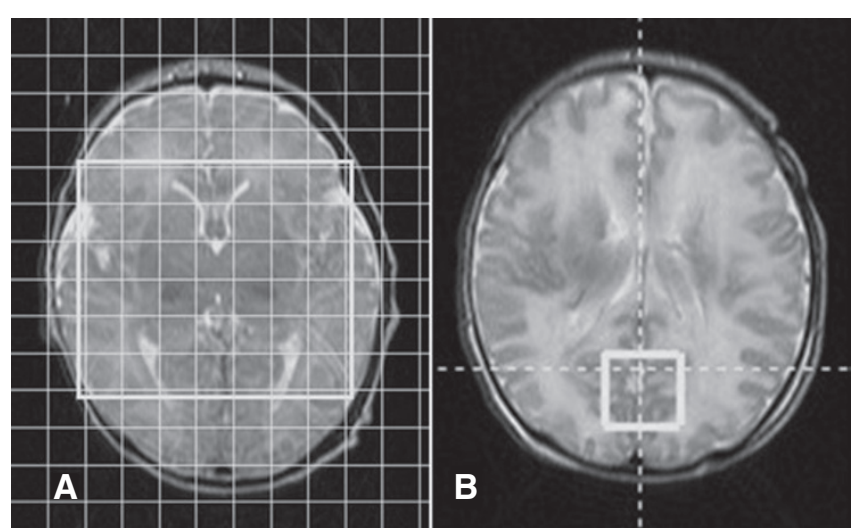

Figure 3. Typical positioning of a magnetic resonance spectroscopic imaging acquisition (a) at the level of the BG and a single-voxel spectroscopy acquisition (b) in the occipital gray matter.

Extracted medical record data included gender, date of birth, gestational age, birth weight and head circumference at birth and discharge, neonatal Apgar scores at 1 and $5 \mathrm{~min}$, need for advanced resuscitation, presence of multiorgan dysfunction, treatment of seizures, antiepileptic drugs used, days on mechanical ventilation, adverse outcomes such as need for gastrostomy at discharge, and death. Laboratory data such as serum glucose, Lac, sodium, potassium, bicarbonate, and hematocrit as well as whole-blood $\mathrm{pH}$ on day of injury and on the day of imaging were recorded if available. Long-term data could not be acquired because a sufficient number of neonates did not return for follow-up.

\section{MRI/MRSI}

MRI/MRS studies were performed using a circularly polarized head coil in a conventional 1.5-T whole-body imaging system (Magnetom Vision; Siemens Medical Systems, Erlangen, Germany). To assess the severity of injury in the BG and watershed cortical regions, sagittal and axial T1-weighted spin-echo (repetition time/echo time, TR/ $\mathrm{TE}=550 / 22 \mathrm{~ms}, 4$ acquisitions, 5-mm-thick slices), axial T2-weighted triple spin-echo (TR/TE1/TE2/TE3 = 3,000/22/60/120 ms), proton density (first echo of the triple-echo sequence; TR/TE $=3,000 / 22 \mathrm{~ms}$ ), and single-shot echo planar diffusion-weighted imaging $(\mathrm{DWI} ; \mathrm{TE}=$ $110 \mathrm{~ms}, 4$-mm-thick slices, $b=0,500,1,000 \mathrm{~s} / \mathrm{mm}^{2}$ ) sequences were acquired. MR images were reviewed by a neuroradiologist (N.W.) and radiology resident (S.M.) and assigned a BG, watershed, and combined $\mathrm{BG}$-watershed MR score using a scoring system previously shown to discriminate between good and poor neuromotor outcomes in asphyxiated neonates (21). Single-voxel spectroscopy of the mid-occipital gray matter (OGM; Figure 3) was acquired using a short-echo-time stimulated-echo acquisition mode $(\mathrm{TR} / \mathrm{TE}=3,000 / 20 \mathrm{~ms}$, voxel size $=2 \mathrm{~mm}^{3}$, number of acquisitions $=128$ ) sequence. A reference spectrum with eight acquisitions and no water suppression was acquired to use for eddy current correction. The OGM was chosen because it is located in a watershed cortical region and our previous studies show that this region is sensitive to global insults $(13,22)$. Quantitative metabolite levels (in institutional units) and ratios were obtained for NAA (2.02 ppm), Cr (Cr + phosphocreatine; $3.0 \mathrm{ppm})$, Cho (3.2 ppm), myo-inositol (3.56 ppm), glutamate/glutamine (2.05 - 2.5), and Lac (1.33 ppm) using LCmodel (35). The metabolite measurements were accepted if the estimated confidence interval (Cramer-Rao lower bound) was $\leq 20 \%$. Two-dimensional MRSI through the level of the BG and TH (Figure 3) was acquired using a point-resolved spectroscopy sequence $(\mathrm{TR} / \mathrm{TE}=3,000 / 144 \mathrm{~ms}, 10$-mm-thick slab, 160 -mm field of view, one acquisition). Spectral post-processing (zero-filling exponential multiplication, Fourier transformation, zero-order phase correction, and baseline correction) was performed (Luise; Siemens Medical Solutions) to obtain NAA/Cr, NAA/Cho, Cho/Cr, and Lac/Cr ratios for each voxel. Ratios from the left and right BG and TH were averaged to obtain mean BG and TH ratios.

Correlations between MRI scores, brain metabolite data, and severity of encephalopathy were also examined. A neonatal encephalopathy score was used to measure the severity and was assigned by an experienced neonatologist (T.A.M.) at discharge. This score is on a 6-point scale from 0 (no encephalopathy) to 6 (severe encephalopathy) on the basis of alertness, feeding, tone, respiratory status, reflexes, and seizure activity, which has previously been validated in term neonates (36).

\section{Statistical Analysis}

Group differences in demographic and clinical measures were assessed using independent samples $t$-test or Mann-Whitney test, as appropriate, and reported as mean $\pm \mathrm{SD}$ or median and minimummaximum values. MRI scores were analyzed using one-way ANOVA with Bonferroni post hoc comparisons and reported as median and minimum-maximum values. MRS/MRSI data were analyzed using one-way ANOVA with Bonferroni post hoc comparisons or $\chi^{2}$ analysis and reported as the mean \pm SD. Correlation coefficients were obtained using Spearman's $\rho$ analysis. All statistical analyses were performed using SPSS for Windows (version 19; SPSS, Chicago, IL) with differences considered significant at $P=0.05$.

\section{REFERENCES}

1. Pin TW, Eldridge B, Galea MP. A review of developmental outcomes of term infants with post-asphyxia neonatal encephalopathy. Eur J Paediatr Neurol 2009;13:224-34.

2. Volpe JJ. Neurology of the Newborn. Philadelphia: WB Saunders, 2008: 331-41.

3. Shankaran S, Laptook AR, Ehrenkranz RA, et al.; National Institute of Child Health and Human Development Neonatal Research Network. Whole-body hypothermia for neonates with hypoxic-ischemic encephalopathy. N Engl J Med 2005;353:1574-84.

4. Azzopardi DV, Strohm B, Edwards AD, et al.; TOBY Study Group. Moderate hypothermia to treat perinatal asphyxial encephalopathy. N Engl J Med 2009;361:1349-58.

5. de Vries LS, Jongmans MJ. Long-term outcome after neonatal hypoxic-ischaemic encephalopathy. Arch Dis Child Fetal Neonatal Ed 2010;95:F220-4.

6. Perlman M, Shah PS. Hypoxic-ischemic encephalopathy: challenges in outcome and prediction. J Pediatr 2011;158:e51-4.

7. Rutherford M, Pennock J, Schwieso J, Cowan F, Dubowitz L. Hypoxicischaemic encephalopathy: early and late magnetic resonance imaging findings in relation to outcome. Arch Dis Child Fetal Neonatal Ed 1996;75:F145-51.

8. Barkovich AJ, Hajnal BL, Vigneron D, et al. Prediction of neuromotor outcome in perinatal asphyxia: evaluation of MR scoring systems. AJNR Am J Neuroradiol 1998;19:143-9.

9. Rutherford M, Srinivasan L, Dyet L, et al. Magnetic resonance imaging in perinatal brain injury: clinical presentation, lesions and outcome. Pediatr Radiol 2006;36:582-92.

10. Ferriero DM, Miller SP. Imaging selective vulnerability in the developing nervous system. J Anat 2010;217:429-35.

11. Hanrahan JD, Sargentoni J, Azzopardi D, et al. Cerebral metabolism within 18 hours of birth asphyxia: a proton magnetic resonance spectroscopy study. Pediatr Res 1996;39:584-90.

12. Cady EB, Amess P, Penrice J, Wylezinska M, Sams V, Wyatt JS. Early cerebral-metabolite quantification in perinatal hypoxic-ischaemic encephalopathy by proton and phosphorus magnetic resonance spectroscopy. Magn Reson Imaging 1997;15:605-11.

13. Ashwal S, Holshouser BA, Tomasi LG, et al. $1 \mathrm{H}$-magnetic resonance spectroscopy-determined cerebral lactate and poor neurological outcomes in children with central nervous system disease. Ann Neurol 1997;41:470-81.

14. Barkovich AJ, Baranski K, Vigneron D, et al. Proton MR spectroscopy for the evaluation of brain injury in asphyxiated, term neonates. AJNR Am J Neuroradiol 1999;20:1399-405. 
15. Roelants-Van Rijn AM, van der Grond J, de Vries LS, Groenendaal F. Value of (1)H-MRS using different echo times in neonates with cerebral hypoxiaischemia. Pediatr Res 2001;49:356-62.

16. Miller SP, Newton N, Ferriero DM, et al. Predictors of 30-month outcome after perinatal depression: role of proton MRS and socioeconomic factors. Pediatr Res 2002;52:71-7.

17. Inder TE, Hunt RW, Morley CJ, et al. Randomized trial of systemic hypothermia selectively protects the cortex on MRI in term hypoxic-ischemic encephalopathy. J Pediatr 2004;145:835-7.

18. Rutherford MA, Azzopardi D, Whitelaw A, et al. Mild hypothermia and the distribution of cerebral lesions in neonates with hypoxic-ischemic encephalopathy. Pediatrics 2005;116:1001-6.

19. Rutherford M, Ramenghi LA, Edwards AD, et al. Assessment of brain tissue injury after moderate hypothermia in neonates with hypoxic-ischaemic encephalopathy: a nested substudy of a randomised controlled trial. Lancet Neurol 2010;9:39-45.

20. Bonifacio SL, Glass HC, Vanderpluym J, et al. Perinatal events and early magnetic resonance imaging in therapeutic hypothermia. J Pediatr 2011;158:360-5.

21. Miller SP, Ramaswamy V, Michelson D, et al. Patterns of brain injury in term neonatal encephalopathy. J Pediatr 2005;146:453-60.

22. Shu SK, Ashwal S, Holshouser BA, Nystrom G, Hinshaw DB Jr. Prognostic value of $1 \mathrm{H}-\mathrm{MRS}$ in perinatal CNS insults. Pediatr Neurol 1997;17:309-18.

23. Cady EB. Metabolite concentrations and relaxation in perinatal cerebral hypoxic-ischemic injury. Neurochem Res 1996;21:1043-52.

24. Barkovich AJ, Westmark KD, Bedi HS, Partridge JC, Ferriero DM, Vigneron DB. Proton spectroscopy and diffusion imaging on the first day of life after perinatal asphyxia: preliminary report. AJNR Am J Neuroradiol 2001;22:1786-94.

25. Amess PN, Penrice J, Wylezinska M, et al. Early brain proton magnetic resonance spectroscopy and neonatal neurology related to neurodevelopmental outcome at 1 year in term infants after presumed hypoxic-ischaemic brain injury. Dev Med Child Neurol 1999;41:436-45.
26. Provencher SW. Estimation of metabolite concentrations from localized in vivo proton NMR spectra. Magn Reson Med 1993;30:672-79.

27. Ashwal S, Holshouser BA, del Rio MJ, Tong KA, Applegate RL, Bailey LL. Serial proton magnetic resonance spectroscopy of the brain in children undergoing cardiac surgery. Pediatr Neurol 2003;29:99-110.

28. Angeles DM, Ashwal S, Wycliffe ND, et al. Relationship between opioid therapy, tissue-damaging procedures, and brain metabolites as measured by proton MRS in asphyxiated term neonates. Pediatr Res 2007;61:614-21.

29. Massaro AN, Kadom N, Chang T, Glass P, Nelson K, Baumgart S. Quantitative analysis of magnetic resonance images and neurological outcome in encephalopathic neonates treated with whole-body hypothermia. J Perinatol 2010;30:596-603.

30. Sarnat HB, Sarnat MS. Neonatal encephalopathy following fetal distress. A clinical and electroencephalographic study. Arch Neurol 1976;33:696-705.

31. Panigrahy A, Blüml S. Advances in magnetic resonance neuroimaging techniques in the evaluation of neonatal encephalopathy. Top Magn Reson Imaging 2007;18:3-29.

32. Panigrahy A, Nelson MD Jr, Blüml S. Magnetic resonance spectroscopy in pediatric neuroradiology: clinical and research applications. Pediatr Radiol 2010;40:3-30.

33. Obenaus A, Ashwal S. Magnetic resonance imaging in cerebral ischemia: focus on neonates. Neuropharmacology 2008;55:271-80.

34. Azzopardi D, Edwards AD. Magnetic resonance biomarkers of neuroprotective effects in infants with hypoxic ischemic encephalopathy. Semin Fetal Neonatal Med 2010;15:261-9.

35. Miller SP, Latal B, Clark H, et al. Clinical signs predict 30-month neurodevelopmental outcome after neonatal encephalopathy. Am J Obstet Gynecol 2004;190:93-9.

36. Groenendaal F, Veenhoven RH, van der Grond J, Jansen GH, Witkamp TD, de Vries LS. Cerebral lactate and N-acetyl-aspartate/choline ratios in asphyxiated full-term neonates demonstrated in vivo using proton magnetic resonance spectroscopy. Pediatr Res 1994;35:148-51. 